\title{
Assessing the Site Potential for Underwater Turbines in Tidal Channels Using Numerical Modeling and Advanced Ocean Current Measurements
}

\author{
David B. Fissel, Jianhua Jiang, Rick Birch, Jan Buermans and David Lemon \\ ASL Environmental Sciences Inc., 1986 Mills Rd., Sidney, BC, V8L 5Y3, Canada, \\ Phone Number (250) 656-0177, dfissel@ aslenv.com
}

\begin{abstract}
A combination of advanced ocean current profiling measurements and high resolution 3D numerical models was used to assess site potential for underwater turbines in tidal channels of the inland waters off the coast of British Columbia, Canada. The measurements involved the use of ADCP transects through potential sites. Due to the very strong tidal currents of up to 10 knots or more, special procedures are required to generate accurate and reliable maps of the very strong ocean currents. The three-dimensional, coastal circulation model COCIRM was used to map these detailed flows under different scenarios and assess the potential at various sites for operation of underwater turbines after validated using available water elevation and ocean current data.
\end{abstract}

\section{INTRODUCTION}

Electricity generation using underwater turbines in areas of strong tidal currents can provide a very dependable and predictable source of clean and renewable energy, often with minimal and/or mitigatible impact on the natural environment. This paper describes a technique combining advanced ocean current profiling measurements and high resolution 3-D numerical models to assess potential sites and address key issues for this emerging energy source. This tool is capable of providing such important information as quantifying the total generation potential, input to detailed engineering design of the underwater turbine system, the effects of the turbine system on ambient flow patterns, and potential environmental impact that may arise.

The suite of ocean current measurements and modeling are presented using the results from recent studies in the passages of the inland waters off the coast of British Columbia, Canada, including Race Rocks, Gillard Passage, Discovery Passage and Canoe Pass. The measurements involved the use of ADCP transects through potential sites. Due to the very strong tidal currents of up to 10 knots or more, special procedures are required to generate accurate and reliable maps of the very strong ocean currents. At sites in the Discovery Passage area off the east coast of Vancouver Island, numerical modeling studies of ocean currents and water levels were carried out using the three-dimensional coastal circulation model COCIRM to assess the potential at various sites for operation of underwater turbines to generate electrical power. One particular site, Canoe Pass, located between Quadra Island and Maud Island in Discovery Pass, British Columbia, features an artificial dam or causeway which blocks the passage of water from Seymour Narrows immediately east of the Pass. As a result, significant water level differences exist between two sides of the dam with the maximum heads up to $1.5 \mathrm{~m}$ during spring tides and $0.8 \mathrm{~m}$ during neap tides. The difference in water levels on either side of the dam has the potential for significant renewable energy through installation of underwater turbines for generating electrical power. Numerical modeling simulations of the currents and water levels were conducted, including the present conditions for model calibration and verification, possible future conditions in which the dam is completely removed and the Pass is restored to its original configuration, and possible future conditions in which the dam is partially removed to allow the passage of water through an underwater turbine. The detailed results of these simulations are reported in this paper.

\section{METHODOLOGY}

\section{A. ADCP Profiling}

ASL has been doing ADCP Transects to measure strong currents in tidal passages since 1994. Initially a RDI BBADCP (Fig. 1) was used, then moving on to the next generation WH series. We bolted the ADCP to the side of the vessel (remember to re-seal the holes below the waterline), taking special care to minimize turbulence around the head by adding an aluminum shroud or fairing and by setting the head of the ADCP fairly deep to minimize the amount of bubbles around the transducers. We still tend to use a fairing if we expect currents greater than 5 knots or so.

Over the years, a 2-pole bracket that fits most smaller boats has been used for mounting the ADCP instrument. For large vessels a custom pole mount is generally required.

Aluminum boats are preferred so that the ADCP compass is reliable but an external gyro or fluxgate compass can be used for steel vessels if necessary. The older BBADCP had a better compass than the newer WH series of ADCPs and gave excellent results.

Transect lines are set up ahead and we use Fugawi for our onboard navigation. We generally use a Garmin GPS with WAAS and combination sounder. The RDI software can bring in both the GPS positions as well as the sounder depths. 


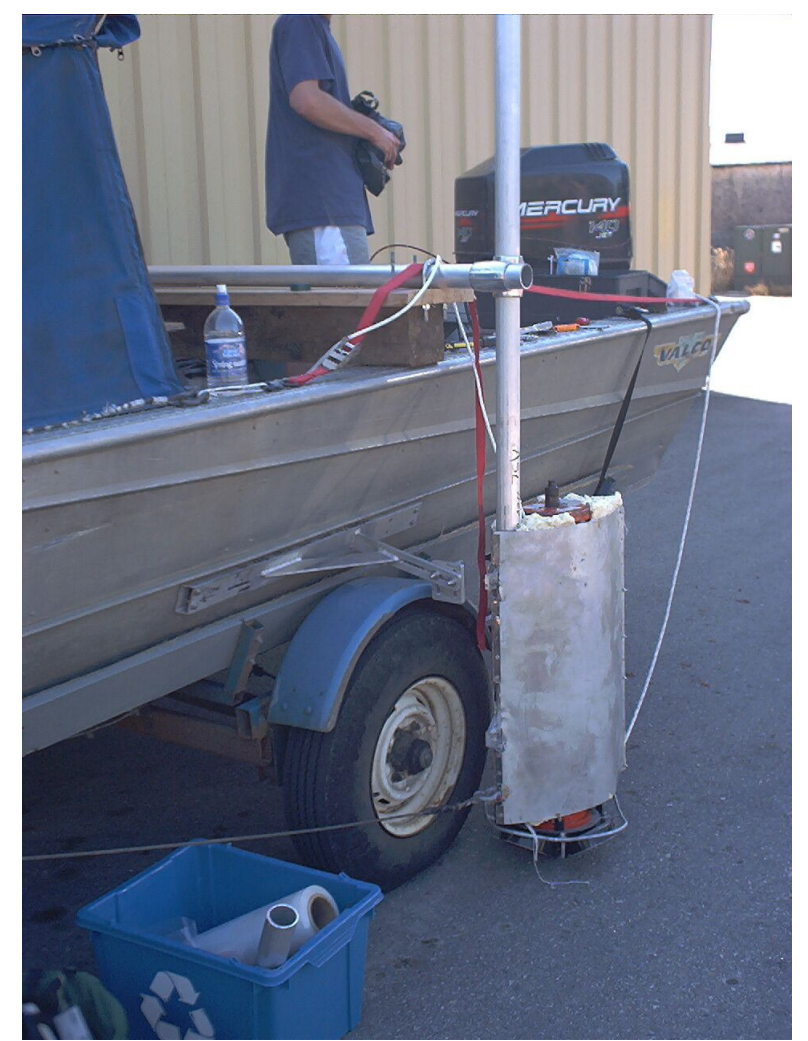

Fig. 1. RDI BBADCP boat-mounted for current transects in high flows.

Transects are planned so that the area of interest can be covered in an hour or less. If taking much longer, the tides change enough that the data are no longer synoptic. Boat speed and bin size are optimized for the flow regime. The rule of thumb is that the boat velocity should not exceed the water velocity. In strong tidal channels with tidal turbine potential, we can normally run the boat at several knots, allowing us to cover larger areas within the hour limit.

Since the ADCP bottom-track (BT) error accumulates over long transect distances, the ADCP velocity vectors are plotted on a map using the lat/long from the GPS. We use Matlab programs to plot the current velocity vectors over a scanned in bathymetric chart or even a Google Earth image if no chart is available.

\section{B. Numerical modeling}

The three-dimensional, coastal circulation numerical model COCIRM was adapted in these studies. The COCIRM model represents a computational fluid dynamics approach to the study of river, estuarine and coastal circulation regimes. The model explicitly simulates such natural forces as pressure heads, buoyancy or density differences due to salinity and temperature, river inflow, meteorological forcing, and bottom and shoreline drags [1, 2, 3]. The model applies the fully three-dimensional basic equations of motion and conservative mass transport combined with a second order turbulence closure model [4] for vertical diffusivity and Smagorinsky's formula [5] for horizontal diffusivity, then solves for timedependent, three-dimensional velocities $(u, v, w)$, salinity $(s)$, temperature $(T)$, turbulence kinetic energy $(k)$ and mixing length $(l)$, horizontal and vertical diffusivities $\left(K_{h}, K_{v}\right)$, and water surface elevation $(\zeta)$. The horizontal grid element sizes are typically in the range of $5-100 \mathrm{~m}$. The water column may be resolved using either sigma or $\mathrm{z}$ grid, with a flexible distribution of typically $10-20$ layers.

To validate it as a reliable tool for the objectives in these studies, the model at first goes through appropriate calibration and verification processes using available water elevation and ocean current data. After validated, the model was then implemented to simulate water levels and ocean currents for different scenarios. The detailed model flows at various vertical levels were mapped and used to assess site potential of installing and operating underwater tidal current turbines, and potential environmental impact that may arise.

The model was initially tested and operated in calibration runs. Various physical parameters, mainly bottom drag coefficient and horizontal and vertical eddy diffusivity coefficients, were repetitively adjusted to achieve optimal agreement with the observations. The vertical diffusivity for the model, as derived from the second order turbulence closure model [4], was found to be robust. Most efforts were involved in testing and adjusting of the bottom drag and the horizontal diffusivity.

Once reasonable agreement is attained for the calibration cases; the model was next operated in validations runs using the previously optimized physical parameters and compared with different observation data sets. The agreement between the model outputs and the observations is used to assess the capabilities of the model. If the comparisons do not meet the model requirements, or indicate that significant further improvements are needed, the calibration processes can be repeated to improve the model performance.

\section{APPLICATIONS}

\section{A. ADCP Surveys}

Currents of up to 8 knots were measured off Middle Point in Discovery Passage. The predicted maximum in Seymour Narrows to the north was just over 15 knots. Reverse flows occurred along the southwest shore (Fig. 2). The strong lateral shear shows the importance of mapping out the currents before deciding where to put a tidal turbine. The data were also used for verification of the numerical model for this area (below). 


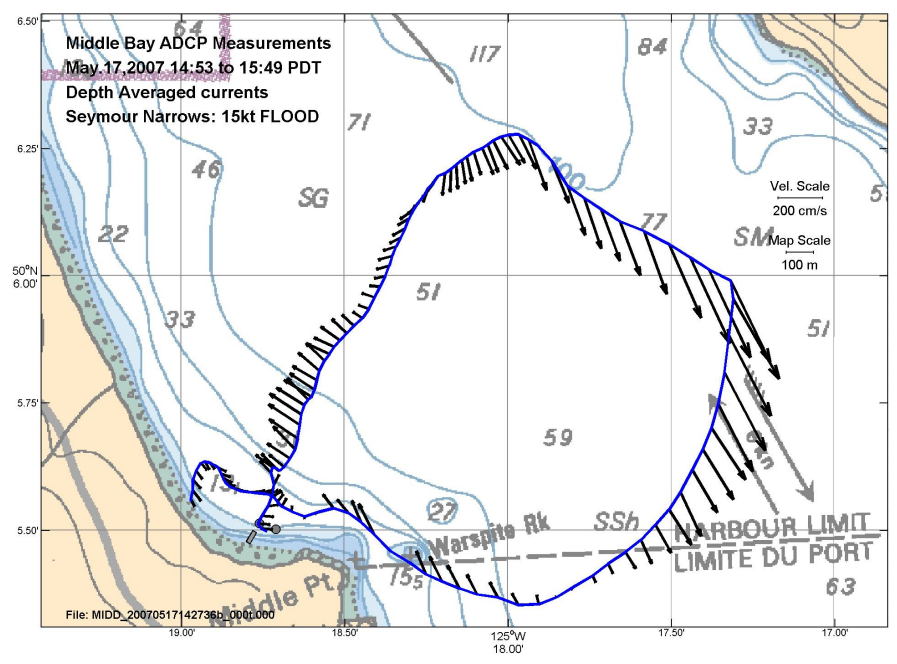

Fig. 2 Depth-averaged currents off Middle Point in Discovery Passage during a spring flood tide.

\section{B. Modeling Flows in Discovery Passage}

In this study, the 3D numerical model COCIRM was applied to simulate the flows in the southern Discovery Passage (Fig. 3). The objective of this study is to provide some preliminary $3 \mathrm{D}$ numerical modeling simulations of the ocean currents, which can be used to investigate the feasible sites for installing and operating underwater tidal current turbines [6].

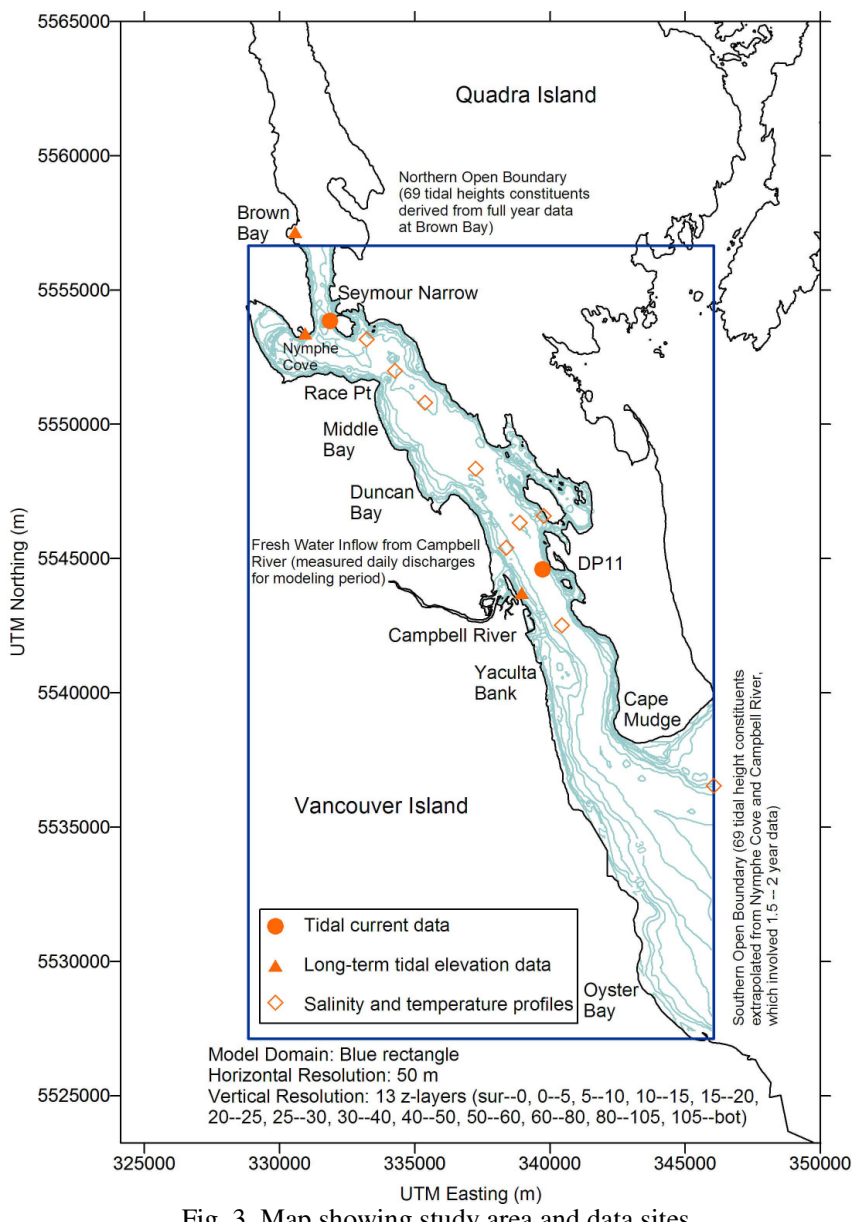

Fig. 3. Map showing study area and data sites.
The model domain includes the portion of Discovery Passage extending from Oyster Bay in the south to Brown Bay in the north, with an area of about $30 \mathrm{~km}$ by $17 \mathrm{~km}$. The whole model domain is resolved by a horizontal grid of size $50 \mathrm{~m}$ by $50 \mathrm{~m}$, and 13 vertical z-coordinate layers with higher resolution near the surface (Fig. 3) in order to appropriately resolve salinity and temperature induced density stratification.

The model involves two open boundaries, respectively the cross-section between Oyster Bay and Cape Mudge to the south and at Brown Bay to the north (Fig, 3). The boundary conditions at these two locations were specified by tidal elevations and inflow salinity and temperature. The tidal elevations at these two open boundaries were derived from 69 tidal height constituents using Foreman's tidal prediction program (Dr. M. Foreman, Institute of Ocean Sciences, Dept. of Fisheries and Oceans, Sidney, B.C., Canada, pers. comm.). The 69 tidal constituents at the northern open boundary were derived from a full year tidal elevation data in Brown Bay. The 69 tidal constituents at the southern open boundary were extrapolated from Nymphe Cove and Campbell River, where $1-2$ year tidal elevation data were used in the tidal analysis. The tidal elevations are assumed to be approximately uniform over the cross-sections of both open boundaries. In COCIRM, geostrophically balanced elevations due to Coriolis force at each open boundary are calculated and superimposed on tidal components at every time step.

The inflow salinity and temperature at the southern open boundary were specified by the monthly salinity and temperature profile data at this boundary [7]. The inflow salinity and temperature at the northern open boundary were extrapolated from the data at the southern open boundary in terms of the salinity and temperature horizontal gradients derived from the CTD-bottle profile data inside Discovery Passage (Fig. 3).

At Campbell River, the freshwater discharges were given in the model, which were retrieved from daily discharges in Canadian Hydrological Data Base. The discharge was assigned a zero salinity (i.e. freshwater) and realistic temperature for each model case.
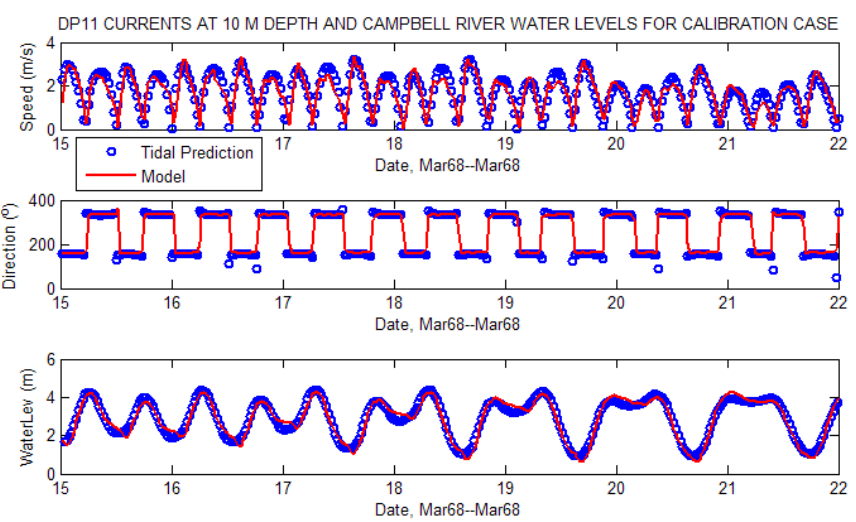

Fig. 4. Calibration model results of DP11 currents at $10 \mathrm{~m}$ depth and Campbell River water levels, with comparisons to the tidal prediction results. 

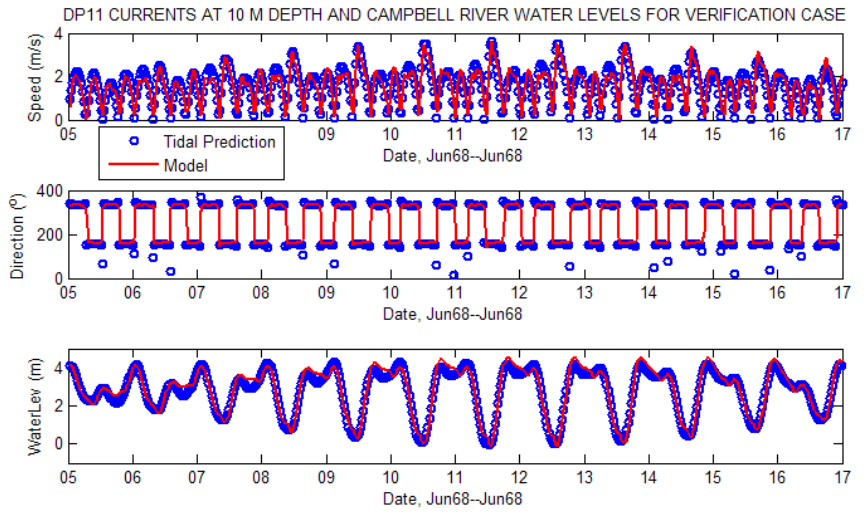

Fig. 5. Verification model results of DP11 currents at $10 \mathrm{~m}$ depth and Campbell River water levels, with comparisons to the tidal prediction results.
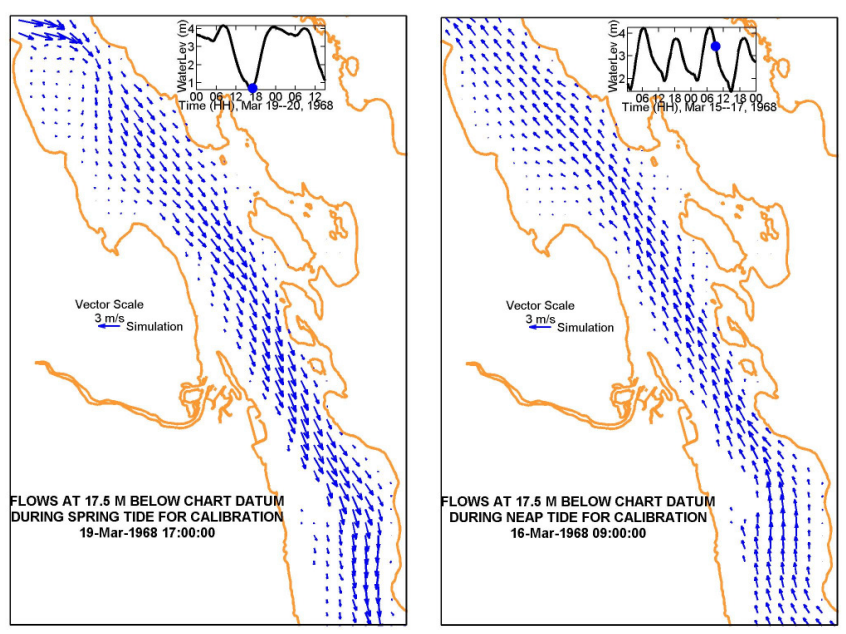

Fig. 6. Model peak flood flows (left panel) and peak ebb flows (right panel) at $17.5 \mathrm{~m}$ below chart datum during a spring tide.

The 3-D model was calibrated and validated by comparison of model output to the tidal analysis results from existing data sets as shown in Fig. 4 and Fig. 5. Good agreement was achieved between model- and data-based currents.

The results of the 3-D current model for peak flood and ebb tidal flow conditions at $17.5 \mathrm{~m}$ depth are shown in Fig. 6. Tidal current results of this type provide the basis for site selection of optimal turbine locations, in combination with considerations of ship traffic routes and site specific environmental considerations.

\section{Modeling Flows in Canoe Pass}

The simulations of ocean currents and water levels using the 3D numerical model COCIRM were carried out for Canoe Pass between Quadra Island and Maude Island in Discovery Pass, British Columbia, Canada (Fig. 7). Canoe Pass has a dam, or barrier, across it which blocks passage of water from Seymour Narrows immediately east of the Pass. The dam has been in place since the 1940's. The numerical model studies are part of a site investigation to assess the potential for operation of underwater turbines to generate electrical power, including past and present conditions, and potential future conditions related to the installation of an underwater turbine.

For this study, the model was operated over an area of about $8 \mathrm{~km}$ by $8 \mathrm{~km}$ in total size using a $50 \mathrm{~m}$ by $50 \mathrm{~m}$ horizontal grid resolution. For an area of $2 \mathrm{~km}$ by $3 \mathrm{~km}$ centred on Canoe Pass, a higher resolution nested grid was incorporated into the model, with a horizontal grid size of 10 $\mathrm{m}$ (Fig. 8). Both $50 \mathrm{~m}$ and $10 \mathrm{~m}$ model grids used 10 equallyspaced vertical sigma-layers, and were coupled at interfaces and solved together every time step with a single modeling procedure using the two-way, dynamic nested grid scheme in COCIRM [2].

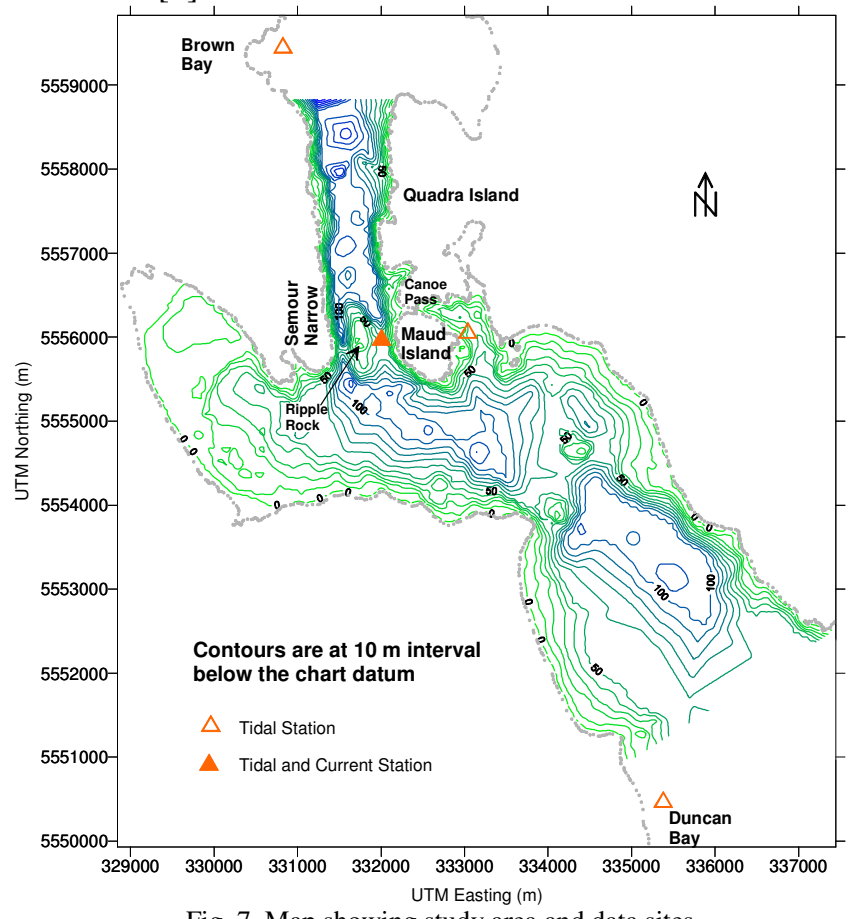

Fig. 7. Map showing study area and data sites.

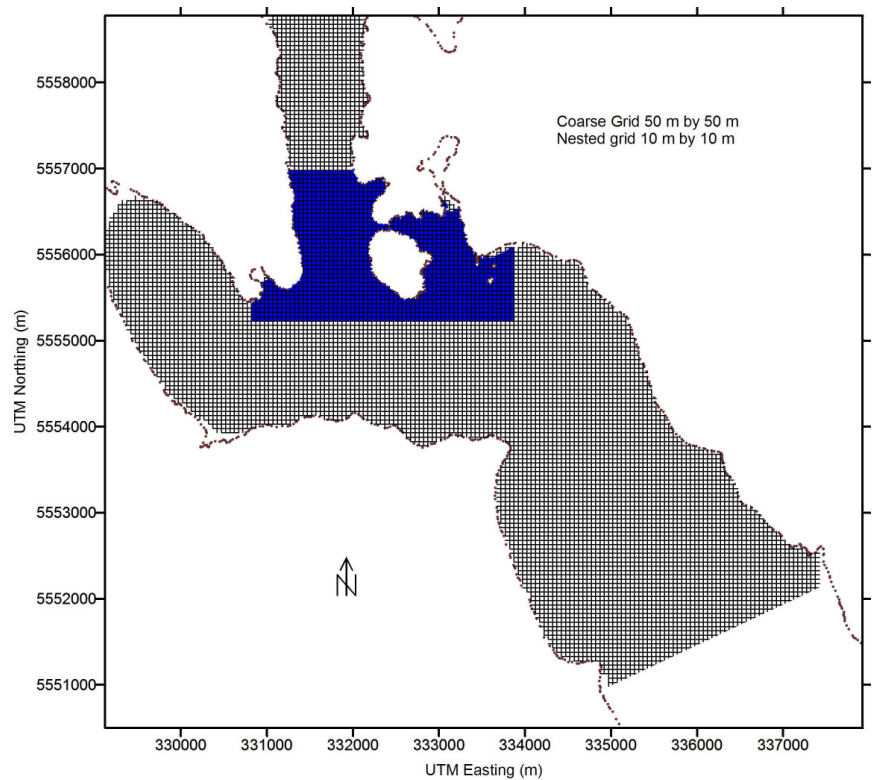

Fig. 8. The numerical model grid developed for this study, with $50 \mathrm{~m}$ and 10 $\mathrm{m}$ linear dimensions for coarse and nested grids, respectively. 
The model involved two open boundaries, respectively in the Duncan Bay in the south and in the Brown Bay in the north (Fig. 7). The boundary conditions at these two locations were specified by tidal elevations, which were computed using 9 major tidal constituents: $\mathrm{O}_{1}, \mathrm{P}_{1}, \mathrm{~K}_{1}, \mathrm{~N}_{2}, \mathrm{M}_{2}, \mathrm{~S}_{2}, \mathrm{~K}_{2}$, $\mathrm{M}_{4}, \mathrm{MS}_{4}$, which were derived by Canadian Hydrographic Service from the field data of 29 days duration in Duncan Bay and of 367 days in Brown Bay. Again, the tidal elevations are assumed to be approximately uniform over the cross-sections of both open boundaries, and geostrophically balanced elevations due to Coriolis force at each open boundary are calculated and superimposed on tidal components at every time step.
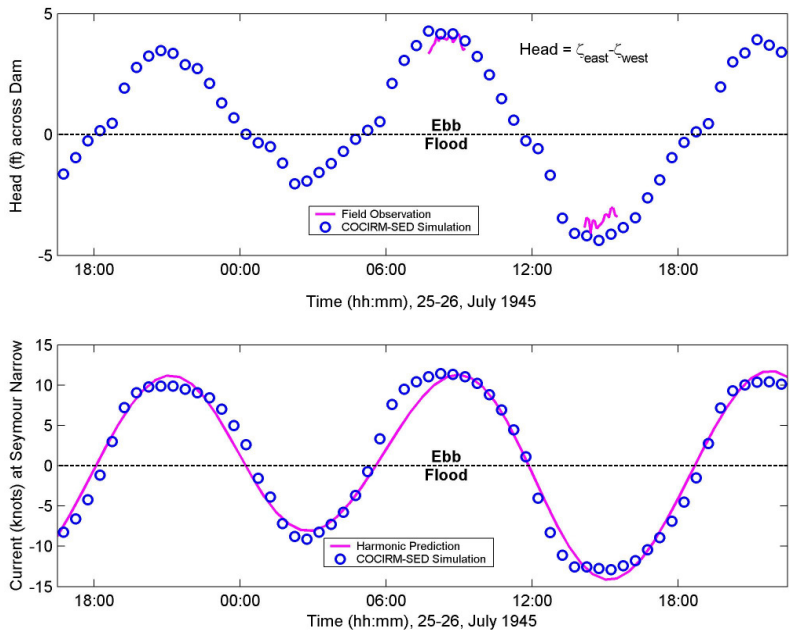

Fig. 9. Model results of water head across the Dam and currents at Seymour Narrow, with comparisons to observations.
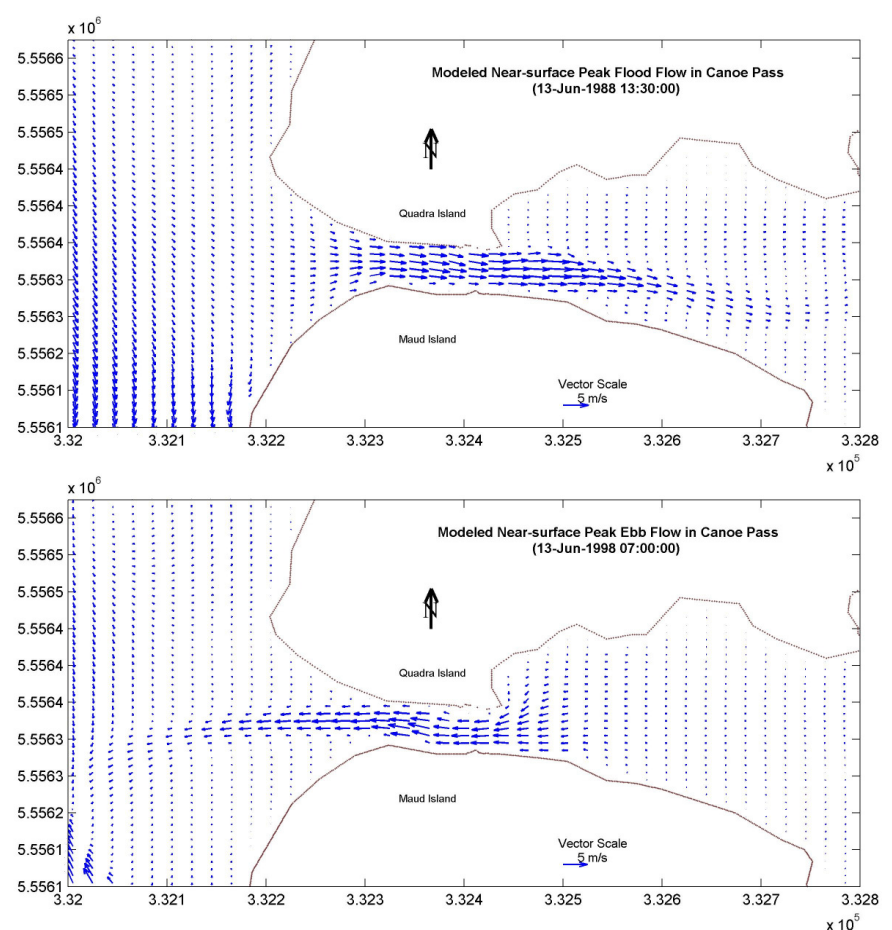

Fig. 10. Peak flood (upper) and ebb (lower) in Canoe Pass with the Dam removed.

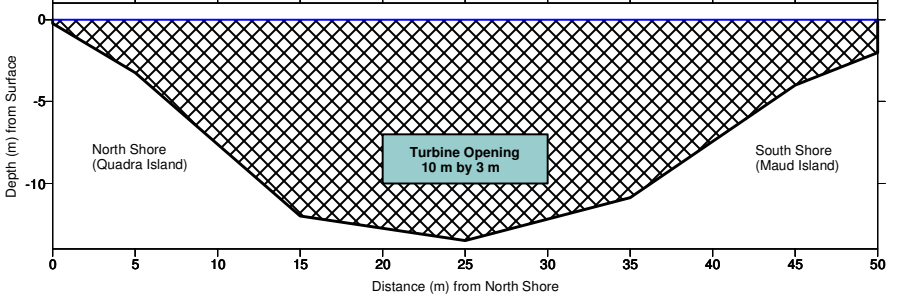

Fig. 11. Map showing the $10 \mathrm{~m}$ by $3 \mathrm{~m}$ opening for turbine.
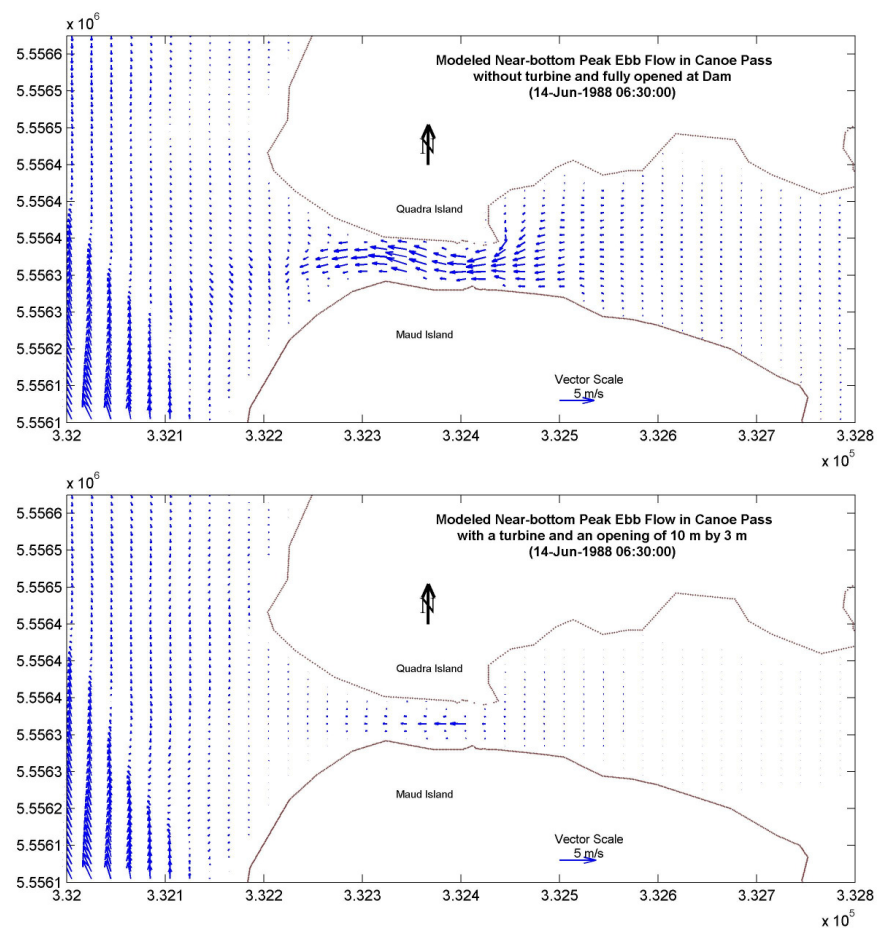

Fig. 12. Model peak ebb flows in Canoe Pass without turbine and with the Dam fully removed (upper), and with a turbine and an opening of $10 \mathrm{~m}$ by 3 $\mathrm{m}$ (lower) for near-bottom currents during large ebb tide conditions.

The model was calibrated by comparisons to water level observations as given in Fig. 9 with good agreement being achieved. Further model validations were obtained by comparing model output with direct current meter measurements made in the Seymour Narrows area using historical oceanographic data sets.

The model was then run to simulate the tidal currents that would result from removal of the dam blocking Canoe Pass and essentially reverting to the conditions before the dam was installed in the 1930's and earlier. Very strong tidal currents would occur through the narrow Pass (Fig. 10).

Finally tidal currents were simulated if only a small portion of the Canoe Pass Dam was removed (Fig. 11) and a turbine was operated in this opening. The model results indicate that the tidal currents in Canoe Pass (Fig. 12) are limited to weak to moderate flows at near-bottom levels, and otherwise very similar to existing conditions. 


\section{CONCLUSION AND DISCUSSION}

The combination of advanced ocean current profiling measurements and high resolution 3D numerical models have been used, over the past several years, to assess site potential for underwater turbines in tidal channels of the inland waters off the coast of British Columbia, Canada. An example of the methodology for advanced ADCP measurements is given for recent work carried out in the Middle Bay portion of Discovery Passage area off the east coast of Vancouver Island, British Columbia, Canada.

The ASL-COCIRM numerical model used in this study is a full three dimensional circulation model, based on the Reynolds-averaged Navier-Stokes fluid dynamics equations, with finite difference volume elements. The model uses a rectilinear grid in the horizontal and, in the vertical, either sigma or $\mathrm{z}$ coordinate grid with a flexible distribution of typically greater than 10 layers. Two modeling studies that were recently carried out in the Discovery Passage area provide examples of the capabilities of very high resolution circulation models for assessing site potential for tidal current generation for both free standing bottom turbines (Middle Bay) and for a turbine mounted with a dam in a very narrow tidal passage (Canoe Pass). The numerical models provide very high resolution of the three dimensional tidal currents at $50 \mathrm{~m}$ horizontal grid size over model domains of tens of kilometers in size. Much high horizontal resolution, of $10 \mathrm{~m}$, is achieved within a nested grid area around potential turbine sites.

The field measurement and numerical modeling capabilities described in this paper provide tidal current development companies with essential information to find the optimal sites for their turbine units, to simulate the operation of the turbine and its effects on the local oceanographic conditions and also to provide a quantitative basis for addressing environmental approval issues.

\section{ACKNOWLEDGMENTS}

We wish to thank our colleagues at ASL who worked on the various projects which formed the basis of this paper. Also our thanks to the Canadian Dept. of Fisheries and Oceans for the historical ocean current, water level and water property data sets used to run the model.

We especially wish to thank our clients, including the consortium of companies involved in the Canoe Pass and Discovery Pass Tidal projects (Clayton Bear and Bob Moll of New Energy Corp; Thor Peterson and Chris Knight of Discovery Pass Tidal Power; Bill Johnston of Focus Environmental) and to the Middle Bay Project (R. Buchanan) and Norman Allyn of Westmar Engineers.

\section{REFERENCES}

[1] J. Jiang, D.B. Fissel, D.D. Lemon and D. Topham, 2002. Modeling cooling water discharges from the Burrard
Generating Station, BC Canada. Proceedings, Oceans 2002 MTS/IEEE, Biloxi, Mississippi, October, 2002.

[2] J. Jiang, D.B. Fissel, and D. Topham, 2003. 3D numerical modeling of circulations associated with a submerged buoyant jet in a shallow coastal environment. Estuarine, Coastal and Shelf Science, 58, 475-486.

[3] D.B. Fissel and J. Jiang, 2008. 3D numerical modeling of flows at the confluence of the Columbia and Pend d'Oreille rivers. In: Estuarine and Coastal Modeling: proceedings of the Tenth International Conference, ed. M.L. Spaulding. American Society of Civil Engineers, in press.

[4] G.L. Mellor and T. Yamada, 1982. Development of a turbulence closure model for geographical fluid problems. Review of Geophysics, 20(4), 851-875.

[5] J. Smagorinsky, 1963. General circulation experiments with the primitive equations: I. the basic experiment. Monthly Weather Review, 91, 99-164.

[6] J. Jiang and D.B. Fissel, 2007. 3D current modeling in Discovery Passage, British Columbia, for site selection of tidal current turbines. Report for BC Tidal Energy Corporation and Marine Current Turbine Ltd. by ASL Environmental Sciences Inc., Sidney, BC, Canada, 19p. + unnumbered Appendices.

[7] Crean, P.B. and A.B. Ages, 1971. Oceanographic records from twelve cruises in the Strait of Georgia and Juan De Fuca Strait 1968. Department of Energy, Mines and Resources Marine Sciences Branch, Victoria, Canada.

[8] Jiang, J. and D.B. Fissel, 2005. Numerical modeling of flows in Canoe Pass: Phase 1 Report. Report for Focus Environmental on behalf of Canoe Pass Tidal Energy Corp and New Energy Corporation Inc. by ASL Environmental Sciences Inc., Sidney BC, Canada, 28p. 